\title{
Enhanced progression of human prostate cancer PC3 cells induced by the microenvironment of the seminal vesicle
}

\author{
M Kumano', H Miyake,', T Kurahashi', K Yamanaka' and M Fujisawa' \\ 'Department of Surgery, Division of Urology, Kobe University Graduate School of Medicine, 7-5-I Kusunoki-cho, Chuo-ku, Kobe 650-00 I 7, Japan
}

The objective of this study was to characterise the mechanism mediating the prostate cancer progression induced by the microenvironment of seminal vesicle (SV). The invasive potential of PC3 cells significantly increased after treatment with extract from SV of NOD/SCID mouse. Among several growth factors and cytokines that were present in the SV extract, transforming growth factor- $\beta_{1}\left(\mathrm{TGF}-\beta_{1}\right)$ significantly enhanced the invasive potential of PC3 cells; however, the additional treatment with neutralising antibody against TGF- $\beta_{1}$ suppressed the enhanced invasive potential induced by the SV extract. Changes in the invasive potential in PC3 cells after treatment with the SV extract and/or TGF- $\beta_{1}$ were in proportion to those in the production of urokinase-type plasminogen activator (UPA) by PC3 cells. Tumour growth as well as the incidence of lymph node metastasis in NOD/SCID mice after the injection of PC3 cells into the SV were significantly greater than those after the injection into the prostate. These findings suggest that the microenvironment of SV enhances the progression of prostate cancer through a stimulated invasive potential, and that enhanced UPA production in prostate cancer cells induced by TGF- $\beta_{1}$ could therefore be one of the most important mechanisms involved in the progression of prostate cancer after SV invasion.

British Journal of Cancer (2008) 98, 356-362. doi:I0.I038/sj.bjc.6604I69 www.bjcancer.com

Published online 8 January 2008

(C) 2008 Cancer Research UK

Keywords: prostate cancer; invasion; seminal vesicle; transforming growth factor- $\beta_{1}$; urokinase-type plasminogen activator

Invasion of prostate cancer cells into the seminal vesicle (SV) is an adverse prognostic factor in patients undergoing radical prostatectomy. Contemporary series analysing outcomes of radical prostatectomy reported that biochemical recurrence occurred in more than $50 \%$ of patients with SV invasion (Sofer et al, 2003; Bloom et al, 2004). However, SV invasion has been shown to lack a systematic relationship with other potential pathological factors indicating a poor prognosis, and there has not been any independent prognostic predictor in patients with SV invasion (Sofer et al, 2003; Masterson et al, 2005). These findings suggest that adverse features of prostate cancer with SV invasion may be due to an acquired aggressive phenotype rather than 'volume effect' as a result of disease progression.

The outcome of cancer progression depends on multiple interactions of cancer cells with various host factors; that is, the interaction of tumour cells with the organ environment modulates the tumorigenic properties by regulating their phenotypes, such as cell proliferation, motility and invasion (Fidler, 1990). A number of studies have demonstrated significant effects of organ microenvironment on the malignant potentials in several types of cancer cells, including prostate cancer, using in vivo experimental models (Gohji et al, 1997; Sato et al, 1997; Alencar et al, 2005). For example, Gohji et al reported that human renal cancer cells implanted in the subcutis of nude mice produced local nonmetastatic tumours, whereas the same cells orthotopically implanted in the kidney resulted in the formation of local tumours and

*Correspondence: Dr H Miyake; E-mail: hideakimiyake@hotmail.com Revised 26 November 2007; accepted 27 November 2007; published online 8 January 2008 metastases to the lungs. Furthermore, they clarified the important role of proteolytic enzymes whose production is influenced by the organ microenvironment, in the progression of implanted renal cell carcinoma cells (Gohji et al, 1997).

To date, the molecular mechanism mediating disease progression following SV invasion has remained largely unknown, and there is no study analysing whether the malignant phenotype of prostate cancer cells is affected by the microenvironment of SV. We, therefore, developed an implantation model of human prostate cancer cells to the SV of immunodeficient mice, resulting in systemic disease progression in vivo, and investigated the mechanism underlying the modulation of malignant potential of human prostate cancer cells induced by the microenvironment of SV.

\section{MATERIALS AND METHODS}

\section{Reagents}

Recombinant human transforming growth factor- $\beta_{1}$ (TGF- $\beta_{1}$ ), basic fibroblast growth factor, hepatocyte growth factor, plateletderived growth factor, granulocyte colony-stimulating factor, antihuman TGF- $\beta_{1}$ antibody, and anti-human epidermal growth factor (EGF) antibody were from R\&D Systems (Minneapolis, MN, USA). Recombinant human EGF, granulocyte monocyte colony-stimulating factor, tumour necrosis factor- $\alpha$, interkeukin- $1 \beta$, interleukin- 6 , fibronectin, and anti-rat $\beta$-tubulin antibody were from Chemicon International (Temecula, CA, USA). Anti-human urokinase-type plasminogen activator (uPA) antibody and quantitative sandwich 
enzyme immunoassay kit for human uPA were from American Diagnostica (Greenwich, CT, USA). Horseradish peroxidaseconjugated anti-mouse IgG antibody was from Amersham Life Science (Arlington Heights, IL, USA). Biotinylated goat anti-mouse IgG was from Vector Laboratories (Burlingame, CA, USA).

\section{Tumour cell line}

PC3, derived from human prostate cancer, was purchased from the American Type Culture Collection (Rockville, MD, USA). Cells were maintained in DMEM (Life Technologies Inc., Gaithersburg, MD, USA) supplemented with $5 \%$ heat-inactivated fetal calf serum.

\section{Preparation of extracts from the SV and prostate}

After 12-week-old nonobese diabetic/severe combined immunodeficient (NOD/SCID) mice (CLEA Japan Inc., Tokyo, Japan) were killed, SV and prostate were harvested, washed with PBS, and disrupted using a sonicator (Ultrasonic Systems Inc., Haverhill, MA, USA). Following centrifugation of the respective extracts of $\mathrm{SV}$ and prostate, each supernatant was stored at $-80^{\circ} \mathrm{C}$ until used.

\section{In vitro cell growth assay}

The effects of extract from the SV or prostate on the in vitro growth of PC3 cells were assessed using MTT (Sigma Chemical Co., St Louis, MO, USA) as described previously (Yamanaka et al, 2005). Briefly, $1 \times 10^{4}$ cells were seeded in each well of 96 -well microtitre plates and allowed to attach overnight. Cells were then treated with various concentrations of either SV or prostate extract diluted with serum-free DMEM/F12. After $48 \mathrm{~h}$ of incubation, $20 \mu \mathrm{l}$ of $5 \mathrm{mg} \mathrm{ml}^{-1}$ MTT in PBS was added to each well, followed by incubation for $4 \mathrm{~h}$ at $37^{\circ} \mathrm{C}$. The formazan crystals were dissolved in DMSO. The optical density was determined with a microculture plate reader (Becton Dickinson Labware, Lincoln Park, NJ, USA) at $540 \mathrm{~nm}$. Absorbance values were normalised to the values obtained for vehicle-treated cells. Each assay was performed in triplicate.

\section{In vitro tumour cell invasion assay}

Tumour cell invasion was measured using cell invasion assay kit (Chemicon) as described previously (Miyake et al, 1999a). Briefly, we used polycarbonate filters with a pore size of $8 \mu \mathrm{m}$ coated with basement membrane Matrigel. The coated filters were placed in Boyden chambers, in the upper compartment of which $1 \times 10^{5}$ cells were suspended in serum-free DMEM/F-12 followed by treatment with extract from the SV or prostate and/or growth factor or cytokine and in the lower compartment of which $25 \mu \mathrm{g} \mathrm{ml}^{-1}$ fibronectin diluted with serum-free DMEM/F-12 were added as a chemoattractant. After $48 \mathrm{~h}$ incubation at $37^{\circ} \mathrm{C}$, cells on the top side of the filter were removed, and cells that had migrated and invaded the Matrigel through the filter and attached to the bottom of the membrane were stained with crystal violet stain solution. The crystal violet stain solution was eluted with $10 \%$ acetic acid extraction buffer and transferred to wells of a 96-well microtitre plate, and the absorbance was read with a microculture plate reader (Becton Dickinson Labware) at $540 \mathrm{~nm}$. Absorbance values were normalised by the values obtained for the vehicle-treated cells. Similarly, cell motility was also assessed using the Boyden chambers without matrigel. Each assay was performed in triplicate.

\section{Measurement of uPA levels in conditioned media}

The concentrations of uPA in conditioned media were determined using a quantitative sandwich enzyme immunoassay kit for human uPA as described previously (Miyake et al, 1999b). Briefly, PC3 cells were seeded in each well of 96-well microtitre plates and allowed to attach overnight. Cells were then treated with extract from the SV, TGF- $\beta_{1}$, and/or anti-TGF- $\beta_{1}$ antibody diluted with serum-free DMEM/F-12. After $48 \mathrm{~h}$ of incubation, serum-free DMEM/F-12 was collected. For each analysis, $100 \mu \mathrm{l}$ of conditioned media were added to microtitre plates coated with a purified polyclonal antibody against human uPA. Bound uPA was detected by an additional biotinylated anti-uPA antibody. After the addition of streptavidin-conjugated horseradish peroxidase, peroxidasemediated conversion of 3,3',5,5'-tetramethylbenzene was measured with a microculture plate reader (Becton Dickinson Labware) at $450 \mathrm{~nm}$. Each assay was performed in triplicate.

\section{Western blot analysis}

Western blot analysis was used to evaluate the expression level of uPA protein in PC3 cells after treatment with extract from the SV and/or anti-TGF- $\beta_{1}$ antibody as described previously (Miyake et al, 1999a). Briefly, samples containing equal amounts of protein $(15 \mu \mathrm{g})$ from lysates of the cultured PC3 cells were electrophoresed on an SDS-polyacrylamide gel and transferred to a nitrocellulose filter. The filters were blocked in PBS containing 5\% nonfat milk powder at $4{ }^{\circ} \mathrm{C}$ overnight and then incubated for $1 \mathrm{~h}$ with a $1: 400$-diluted antihuman uPA mouse antibody or 1:10000-diluted anti-rat $\beta$-tubulin mouse antibody. The filters were then incubated for $30 \mathrm{~min}$ with horseradish peroxidase-conjugated anti-mouse IgG antibody, and specific proteins were detected using an enhanced chemiluminescence western blotting analysis system (Amersham Life Science).

\section{Assessment of in vivo tumour growth}

Male NOD/SCID mice, 10- to 12-week-old, (CLEA Japan Inc.) were housed in a controlled environment at $22^{\circ} \mathrm{C}$ on a 12-h light and $12-\mathrm{h}$ dark cycle. Animals were maintained in accordance with the National Institutes of Health Guide for the Care and Use of Laboratory Animals. Each experimental group consisted of 10 mice. PC3 cells were trypsinised, washed twice with PBS, and $5 \times 10^{5}$ cells suspended in $20 \mu$ l of PBS were directly injected into the SV or the dorsal love of the prostate under the prostatic capsule. Eight weeks after the injection of tumour cells, the mice were killed and the presence of metastasis was macroscopically examined in all abdominal organs, and the weight of each tumour formed in the SV or prostate was measured.

\section{Statistical analysis}

Differences between the two groups were compared using the $\chi^{2}$-test, unpaired $t$-test or Mann-Whitney $U$-test. All statistical calculations were performed using Statview 5.0 software (Abacus Concepts Inc., Berkley, CA, USA), and $P$-values $<0.05$ were considered significant.

\section{RESULTS}

\section{Changes in the malignant phenotype of PC3 cells induced by extract from the SV or prostate}

We initially evaluated the effects of SV or prostate extract on the malignant potential of PC3 cells. As shown in Figure 1, neither the SV or prostate extract had any impact on cell growth or motility of PC3 cells. However, despite the lack of significant effect of prostate extract on the invasive potential of PC3 cells, treatment of PC3 cells with SV extract increased the invasive potential in a dosedependent manner.

\section{Influence of growth factors and cytokines on the invasive} potential of PC3 cells

To identify candidate factor responsible for the enhanced invasive potential of PC3 cells induced by SV extract, the abilities of 10 

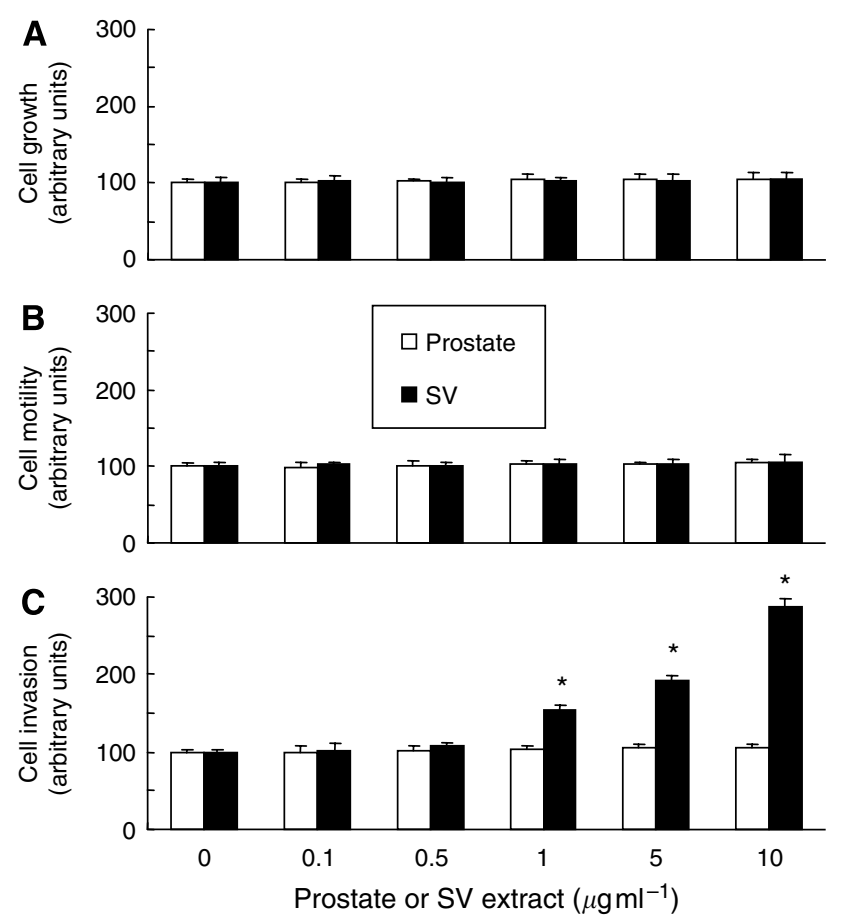

analysed the role of $\mathrm{uPA}$, one of the most important proteolytic enzymes involved in tumour cell invasion (Festuccia et al, 1998), in this process. Treatment of PC 3 cells by TGF- $\beta_{1}$ resulted in a dosedependent increase in uPA production released in the culture medium (Figure 3A). Furthermore, the SV extract also induced increased UPA production by PC3 cells in a dose-dependent manner; however, this stimulated production of uPA by treatment with the SV extract was significantly inhibited by additional treatment with anti-TGF- $\beta_{1}$ antibody (Figure $3 \mathrm{~B}$ ). Western blot analysis was used to measure changes in the expression levels of uPA protein in PC3 cells following treatment with SV extract and/ or anti-TGF- $\beta_{1}$ antibody. As shown in Figure 3C, uPA protein expression in PC3 cells was enhanced by treatment with SV extract in a dose-dependent manner, whereas treatment with anti-TGF- $\beta_{1}$ antibody resulted in the suppression of enhanced uPA protein expression by the SV extract in PC3 cells.

\section{Disease progression following the injection of PC3 cells into the SV in NOD/SCID mice}

To compare the effects of organ microenvironment between SV and prostate on the disease progression of PC3 tumours in vivo, we injected PC3 cells into either the SV or prostate in NOD/SCID mice. The mice were killed 8 weeks after the tumour cell injection, during which we found that the weight of tumours in mice receiving SV injection was significantly greater than that in mice receiving prostate injection. Furthermore, the incidence of retroperitoneal lymph node metastases in mice receiving SV injection was significantly higher than that in mice receiving prostate injection (Table 1). In addition, haemorrhagic ascites was observed only in the mice following SV injection.

Figure I Effects of treatment with extract of either prostate or semina vesicle (SV) on malignant phenotypes, including cell growth, motility and invasion, in human prostate cancer PC 3 cells. (A) PC 3 cells were treated with various concentrations of the prostate or SV extract diluted with serum-free DMEM/FI2. After $48 \mathrm{~h}$ of incubation, the number of viable cells was determined by the MTT assay. Columns, mean of three independent experiments; bars, s.d. (B) PC3 cells seeded at $1 \times 10^{5}$ per well in Boyden chambers were treated with various concentrations of the prostate or SV extract diluted with serum-free DMEM/FI2. Chambers were incubated for $48 \mathrm{~h}$ in serum-free DMEM/FI2, and then cells that had migrated to the lower surface of filters were stained with crystal violet stain solution. After the elution of crystal violet, the absorbance value in each well was measured with a microculture plate reader. Columns, mean of three independent experiments; bars, s.d. (C) PC3 cells seeded at I $\times 10^{5}$ per well in Boyden chambers were treated with various concentrations of the prostate or SV extract diluted with serum-free DMEM/FI2. Chambers were incubated for $48 \mathrm{~h}$, and then cells that had migrated to the lower surface of filters through reconstituted basement membrane Matrigel were stained with crystal violet stain solution. After the elution of crystal violet, the absorbance value in each well was measured with a microculture plate reader. Columns, mean of three independent experiments; bars, s.d. *, differs from control $(P<0.01)$.

kinds of growth factors or cytokines to increase the invasive potential of PC3 cells were evaluated. Of the 10 factors tested, TGF- $\beta_{1}$ and EGF significantly stimulated the invasive potential of PC3 cells (Figure 2A). Furthermore, treatment with both TGF- $\beta_{1}$ and EGF increased in the invasive potential of PC3 cells in dosedependent manners (Figure 2B). We then examined whether antibody against TGF- $\beta_{1}$ or EGF suppresses the enhanced invasive potential of PC3 cells induced by the SV extract. As shown in Figure $2 \mathrm{C}$, anti-TGF- $\beta_{1}$ antibody inhibited the invasive potential of PC3 cells in a dose-dependent manner, while the invasive ability of PC3 cells stimulated by SV extract was not affected by anti-EGF antibody. These results suggest that TGF- $\beta_{1}$ in seminal plasma may be involved in the enhanced invasive potential of PC3 cells induced by the SV extract.

\section{Regulation of uPA production in PC3 cells by TGF- $\beta_{1}$}

To investigate the mechanism mediating the stimulation of invasive potential of PC 3 cells by treatment with TGF- $\beta_{1}$, we

\section{DISCUSSION}

Although SV invasion has been regarded as one of the most potent factors related to an adverse prognosis in patients undergoing radical prostatectomy (Sofer et al, 2003; Bloom et al, 2004), the molecular mechanism mediating the progression of prostate cancer following the invasion of cancer cells into the SV remains largely unknown. To date, a number of studies have demonstrated a significant impact of organ microenvironment on disease progression of various types of human malignant tumours (Gohji et al, 1997; Sato et al, 1997; Alencar et al, 2005); however, there have not been any studies investigating the significance of the SV microenvironment as a factor influencing the progression of prostate cancer. In this study, therefore, we focused on the role of microenvironment of the SV, and evaluated its effects on changes in malignant phenotypes of human prostate cancer PC3 cells both in vitro and in vivo.

It was initially examined whether the SV or prostate extract influences the malignant potential of PC3 cells, and demonstrated that despite the lack of a significant effect of prostate extract, the invasive potential of PC3 cells was markedly enhanced by SV extract. To identify the factors in SV extract mediating the stimulation of invasive potential, we examined the effects of 10 different growth factors or cytokines that have been shown to be abundantly present in seminal plasma (Matalliotakis et al, 1998; Robertson, 2005) and/or associated with the invasion of prostate cancer cells (Barton et al, 2001; Bindukumar et al, 2005). Of the 10 factors examined in this study, TGF- $\beta_{1}$ and EGF were found to significantly stimulate the invasive potential of PC3 cells; however, anti-TGF- $\beta_{1}$ antibody, but not anti-EGF antibody, suppressed the enhanced invasive potential of PC3 cells induced by SV extract. These findings suggest that TGF$\beta_{1}$ may, at least in part, be involved in the increased invasive potential of PC3 cells induced by SV extract.

It is of interest to clarify the mechanism by which TGF- $\beta_{1}$ induces the increased invasive potential of PC3 cells. Several 

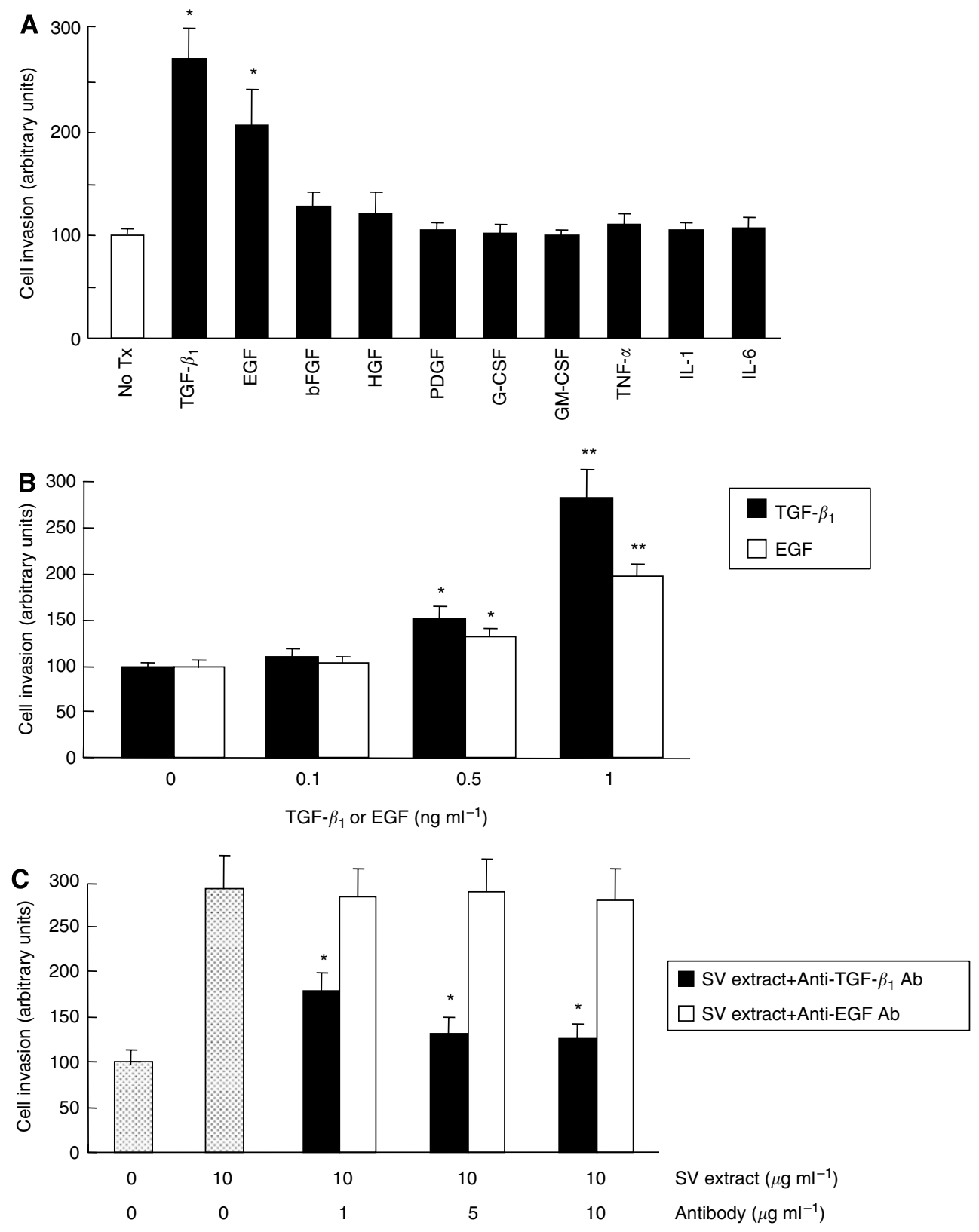

Figure 2 Effects of treatment with growth factors and cytokines on invasive potential in human prostate cancer PC3 cells. (A) PC3 cells seeded at I $\times 10^{5}$ per well in Boyden chambers were treated with I $\mathrm{ng} \mathrm{ml}^{-1}$ transforming growth factor- $\beta_{1}$ (TGF- $\left.\beta_{1}\right), \mathrm{Ing} \mathrm{ml}^{-1}$ epidermal growth factor (EGF), I0 ng ml ${ }^{-1}$ basic fibroblast growth factor (bFGF), $10 \mathrm{ng} \mathrm{ml} \mathrm{l}^{-1}$ hepatocyte growth factor (HGF), platelet-derived growth factor (PDGF), IO ng ml ${ }^{-1}$ granulocyte colonystimulating factor (G-CSF), $10 \mathrm{ng} \mathrm{ml}^{-1}$ granulocyte monocyte colony-stimulating factor (GM-CSF), $100 \cup \mathrm{ml}^{-1}$ tumour necrosis factor- $\alpha$ (TNF- $\alpha$ ), $100 \cup \mathrm{ml}^{-1}$ interkeukin-I $\beta$ (IL-I $\beta$ ) or $10 \mathrm{ng} \mathrm{ml}^{-1}$ interleukin-6 (IL-6) diluted with serum-free DMEM/FI2. Chambers were incubated for $48 \mathrm{~h}$, and then cells that had migrated to the lower surface of filters through reconstituted basement membrane Matrigel were stained with crystal violet stain solution. After the elution of crystal violet, the absorbance value in each well was measured with a microculture plate reader. No Tx, untreated cells. Columns, mean of three independent experiments; bars, s.d. *, differs from control $(P<0.0 I)$. (B) PC3 cells seeded at $1 \times 10^{5}$ per well in Boyden chambers were treated with various doses of TGF- $\beta_{1}$ or EGF diluted with serum-free DMEM/FI2. Chambers were incubated for $48 \mathrm{~h}$, and then cells that had migrated to the lower surface of filters through reconstituted basement membrane Matrigel were stained with crystal violet stain solution. After the elution of crystal violet, the absorbance value in each well was measured with a microculture plate reader. Columns, mean of three independent experiments; bars, s.d. *** and * differs from control $\left(P<0.01\right.$ and $P<0.05$, respectively). (C) PC3 cells seeded at $\mid \times 10^{5}$ per well in Boyden chambers were treated with $10 \mu \mathrm{g} \mathrm{ml}^{-1}$ seminal vesicle extract and various doses of anti-TGF- $\beta_{1}$ or anti-EGF antibody diluted with serum-free DMEM/FI 2 . Chambers were incubated for $48 \mathrm{~h}$, and then cells that had migrated to the lower surface of filters through reconstituted basement membrane Matrigel were stained with crystal violet stain solution. After the elution of crystal violet, the absorbance value in each well was measured with a microculture plate reader. Columns, mean of three independent experiments; bars, s.d. *, differs from control $(P<0.0 \mathrm{I})$.

previous studies have shown that TGF- $\beta_{1}$ enhances the secretion of proteolytic enzymes in prostate cancer cells, which helps degrade the connective tissue extracellular matrix and basement membrane components (Festuccia et al, 2000; Unlu and Leake, 2003). Among these enzymes involved in tumour cell invasion, uPA is one of the most predominant factors involved in the disease progression of malignant tumours (Choong and Nadesapillai, 2003). In prostate cancer as well, accumulating evidence strongly suggests the important role of uPA in the disease progression of prostate cancer (Pulukuri et al, 2005; Usher et al, 2005; Shariat et al, 2007). 

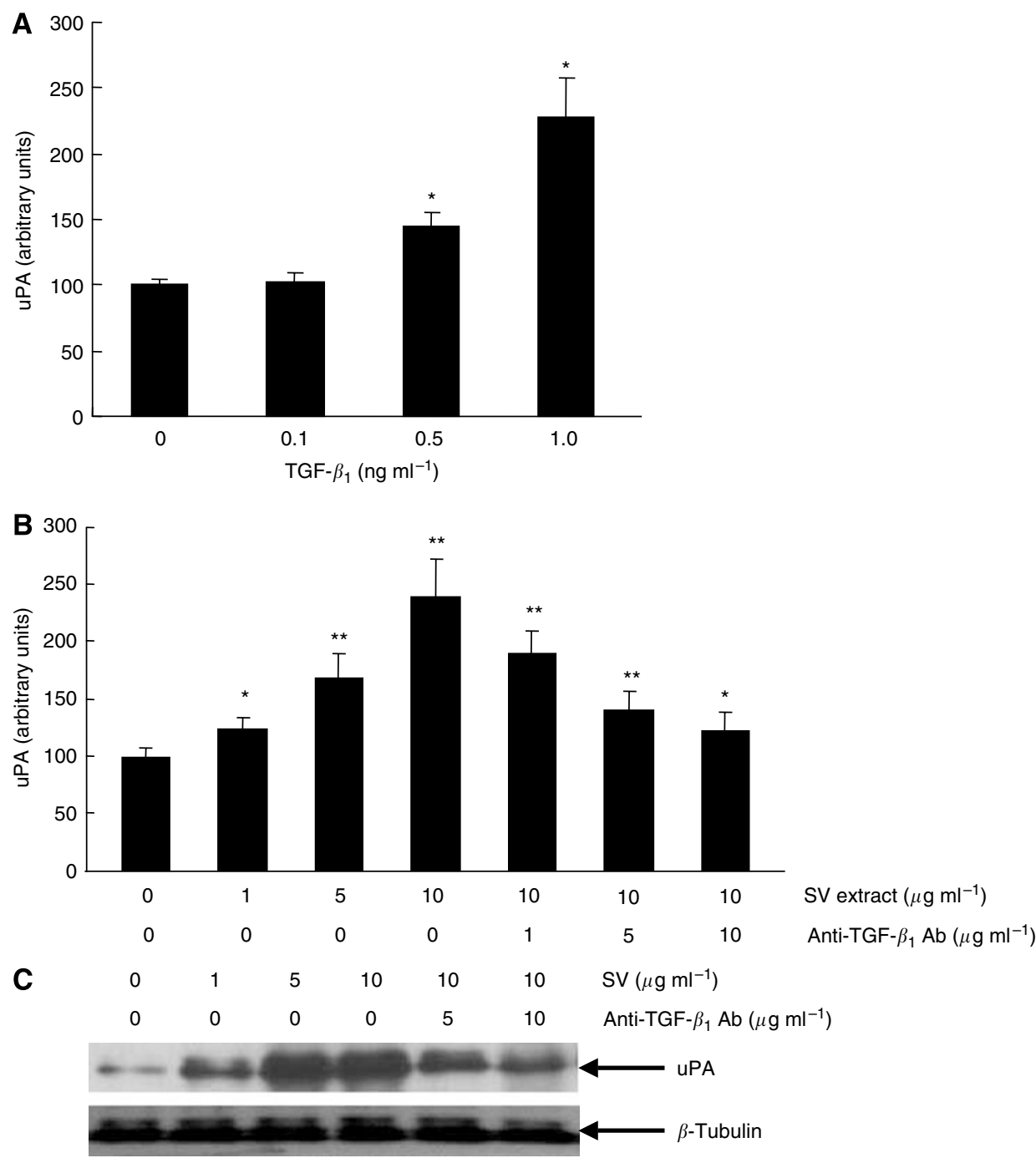

Figure 3 Regulation of urokinase-type plasminogen activator production in human prostate cancer PC3 cells by transforming growth factor- $\beta_{1}$ (TGF- $\beta_{1}$ ) (A) PC3 cells were treated with various concentrations of TGF- $\beta$, diluted with serum-free DMEM/FI 2 . After $48 \mathrm{~h}$ of incubation, serum-free DMEM/FI 2 was collected, and the concentration of uPA in each sample was determined with a quantitative sandwich enzyme immunoassay kit for human uPA. Columns, mean of three independent experiments; bars, s.d. *, differs from control $(P<0.01)$. (B) PC3 cells were treated with various concentrations of seminal vesicle (SV) extract and anti-TGF- $\beta_{\text {I }}$ antibody diluted with serum-free DMEM/FI2. After $48 \mathrm{~h}$ of incubation, serum-free DMEM/FI $2 \mathrm{was}$ collected, and the concentration of UPA in each sample was determined with a quantitative sandwich enzyme immunoassay kit for human uPA. Columns, mean of three independent experiments; bars, s.d. *** and *, differs from control $(P<0.0$ I and $P<0.05$, respectively). (C) PC-3 cells were treated with various concentrations of SV extract and/or anti-TGF- $\beta_{1}$ antibody diluted with serum-free DMEM/FI2. After $48 \mathrm{~h}$ of incubation, protein was extracted from culture cells, and uPA and $\beta$-tubulin protein levels were analysed by western blotting.

Table I Comparison of disease progression in vivo following the injection of PC3 cells into the prostate or SV

\begin{tabular}{lccc}
\hline & Prostate injection & SV injection & P-value \\
\hline Incidence of lymph node metastasis (\%) & $2 / 10(20)$ & $7 / 10(70)$ & $<0.05$ \\
Incidence of haemorrhagic ascites (\%) $^{\mathrm{b}}$ & $0 / 10(0)$ & $4 / 10(40)$ & $<0.05$ \\
Weight of the primary tumor (mg) & $22.8 \pm 8.7$ & $40.7 \pm 10.6$ & $<0.01$ \\
\hline
\end{tabular}

$\mathrm{SV}=$ seminal vesicle. ${ }^{\mathrm{a}} \mathrm{No}$. of mice with lymph node metastases/no. of injected mice. ${ }^{\mathrm{b}} \mathrm{No}$. of mice with haemorrhagic ascites/no. of injected mice. ${ }^{\mathrm{M}}$ Mean $\pm \mathrm{s.d}$.

For example, Pulukuri et al (2005) reported that RNA interferencedirected knockdown of uPA and its receptor in PC3 cells significantly reduced tumour cell viability and invasion, and ultimately resulted in the induction of apoptotic cell death. Considering these findings, in this study, we analysed the TGF$\beta_{1}$-induced stimulation of invasive potential in PC3 cells focusing on the role of uPA. Interestingly, treatment of PC3 cell with TGF- $\beta_{1}$ enhanced their secretion of uPA in a dose-dependent manner. In addition, inhibition of TGF- $\beta_{1}$ activity in the SV extract resulted in the suppression of uPA production in PC3 cells, which was proportional to their invasive potential. Collectively, these results indicated the potential role of UPA in TGF- $\beta_{1}$-mediated enhanced invasive potential of PC3 cells.

To compare the different effects of organ microenvironment between the SV and prostate on disease progression in vivo, we directly injected PC3 cells into the SV or prostate in NOD/SCID 
mice. A number of studies have demonstrated that cancer cells, including prostate cancer, can achieve favourable environments for disease progression in anatomically relevant (i.e., orthotopic) organs (Gohji et al, 1997; Sato et al, 1997; Alencar et al, 2005). In this study as well, lymph node metastases was observed in some mice following injection of PC3 cells into the prostate as described previously (Saffran et al, 2001); however, disease progression in mice following the SV injection of PC3 cells was more prominent than that in mice following intraprostatic injection. Furthermore, we performed in vivo experiments injecting androgen-dependent human prostate cancer $\mathrm{LNCaP}$ cells into the SV or the prostate of NOD/SCID mice, and demonstrated that tumour growth as well as the incidence of lymph node metastasis after the injection of LNCaP cells into the SV were significantly greater than those after the injection into the prostate (data not shown). To our knowledge, this is the first study clearly showing that SV rather than the orthotopic organ (i.e., prostate) provides a stimulating environment for the progression of prostate cancer cells.

Here, we would like to emphasise several limitations of this study. First, the phenomenon of uPA induction by TGF- $\beta_{1}$ may not be entirely responsible for the enhanced invasive potential of PC3 cells by treatment with SV extract; that is, other molecules present in the SV may be involved in promoting the invasive potential. In addition, different mechanisms associated with the microenvironment of the SV, such as the regulated production of proteolytic enzymes by organ-specific fibroblasts (Gohji et al, 1997), may have a significant impact on the disease progression following the injection of PC3 cells into the SV. In fact, despite the lack of a stimulatory effect of SV extract on the proliferation of PC3 cells, injection of PC3 cells into the SV resulted in the enhanced growth of PC3 tumours, suggesting the involvement of a mechanism other than the SV extract-induced enhanced invasive potential of PC3 cells in the disease progression of PC3 tumours in vivo. It is also a limitation that the findings presented in this study may not be uniformly true for a wide variety of cancer cells, considering a divergent function of TGF- $\beta_{1}$ in modulating the malignant phenotype of cancer cells (Desruisseau et al, 1996; Tuxhorn et al, 2002). Finally, we could not show in vivo data supporting the hypothesis of this study; that is, there were no characteristic findings on histological examinations of both tumours developed after the injection of PC3 cells into the SV and the prostate, such as those suggesting different metastatic potentials, and both tumours were shown to exhibit strong uPA expression by immunohistochemical staining (data not shown), which may be due to the originally high expression level of uPA in PC3 cells, resulting in the lack of evident difference in uPA expression between tumours in the SV and the prostate. Accordingly, to enhance the reliability of our findings, the outcomes of this study should be confirmed using different kinds of human prostate cancer model systems.

In conclusion, the findings presented in this study suggest that the microenvironment of SV enhances the progression of prostate cancer through a stimulated invasive potential, and that enhanced uPA production in prostate cancer cells induced by TGF- $\beta_{1}$, which is abundantly present in seminal plasma, could therefore be one of the most important mechanisms involved in the progression of prostate cancer following SV invasion. To address the functional impact of TGF- $\beta_{1}$-induced uPA production on the progression of prostate cancer in the microenvironment of SV, it would be absolutely necessary to perform further experiments characterising changes in malignant phenotype of PC3 cells both in vitro and in vivo before and after the inactivation of TGF- $\beta_{1}$ and/or uPA.

\section{REFERENCES}

Alencar H, King R, Funovics M, Stout C, Weissleder R, Mahmood U (2005) A novel mouse model for segmental orthotopic colon cancer. Int J Cancer 117: $335-339$

Barton J, Blackledge G, Wakeling A (2001) Growth factors and their receptors: new targets for prostate cancer therapy. Urology 58: 114-122

Bindukumar B, Schwartz SA, Nair MP, Aalinkeel R, Kawinski E, Chadha KC (2005) Prostate-specific antigen modulates the expression of genes involved in prostate tumor growth. Neoplasia 7: 241-252

Bloom KD, Richie JP, Schultz D, Renshaw A, Saegaert T, D'amico AV (2004) Invasion of seminal vesicles by adenocarcinoma of the prostate: PSA outcome determined by preoperative and postoperative factors. Urology 63: $333-336$

Choong PF, Nadesapillai AP (2003) Urokinase plasminogen activator system: a multifunctional role in tumor progression and metastasis. Clin Orthop Relat Res 415: S46-S58

Desruisseau S, Ghazarossian-Ragni E, Chinot O, Martin PM (1996) Divergent effect of TGFbetal on growth and proteolytic modulation of human prostatic-cancer cell lines. Int J Cancer 66: 796-801

Festuccia C, Angelucci A, Gravina GL, Villanova I, Teti A, Albini A, Bologna M (2000) Osteoblast-derived TGF-betal modulates matrix degrading protease expression and activity in prostate cancer cells. Int J Cancer 85: $407-415$

Festuccia C, Dolo V, Guerra F, Violini S, Muzi P, Pavan A, Bologna M (1998) Plasminogen activator system modulated invasive capacity and proliferation in prostatic tumor cells. Clin Exp Metastasis 16: 513-528

Fidler IJ (1990) Critical factors in the biology human cancer metastasis: twenty-eighth G. G. A. Clowes memorial award lecture. Cancer Res 50: $6130-6138$

Gohji K, Nakajima M, Boyd D, Dinney CP, Bucana CD, Kitazana S, Kamidono S, Fidler IJ (1997) Organ-site dependence for the production of urokinase-type plasminogen activator and metastasis by human renal cell carcinoma cells. Am J Pathol 151: $1655-1661$

Masterson TA, Pettus JA, Middleton RG, Stephenson RA (2005) Isolated seminal vesicle invasion imparts better outcomes after radical retropubic prostatectomy for clinically localized prostate cancer: prognostic stratification of $\mathrm{pt} 3 \mathrm{~b}$ disease by nodal and margin status. Urology 66: $152-155$

Matalliotakis I, Sifakis S, Goumemou A, Fragouli Y, Neonaki M, Matalliotakis G, Koumantakis E (1998) Cytokine levels in seminal plasma. Clin Exp Obstet Gynecol 25: 58-60

Miyake H, Hara I, Gohji K, Yamanaka K, Hara S, Arakawa S, Nakajima M, Kamidono S (1999a) Relative expression of matrix metalloproteinase- 2 and tissue inhibitor of metalloproteinase-2 in mouse renal cell carcinoma cells regulates their metastatic potential. Clin Cancer Res 5: $2824-2829$

Miyake H, Hara I, Yamanaka K, Gohji K, Arakawa S, Kamidono S (1999b) Elevation of serum levels of urokinase-type plasminogen activator and its receptor is associated with disease progression and prognosis in patients with prostate cancer. Prostate 39: 123-129

Pulukuri SM, Gondi CS, Lakka SS, Jutla A, Estes N, Gujrati M, Rao JS (2005) RNA interference-directed knockdown of urokinase plasminogen activator and urokinase plasminogen activator receptor inhibits prostate cancer cell invasion, survival, and tumorigenicity in vivo. J Biol Chem 280: $36529-36540$

Robertson SA (2005) Seminal plasma and male factor signalling in the female reproductive tract. Cell Tissue Res 322: $43-52$

Saffran DC, Raitano AB, Hubert RS, Witte ON, Reiter RE, Jakobovits A (2001) Anti-PSCA mAbs inhibit tumor growth and metastasis formation and prolong the survival of mice bearing human prostate cancer xenografts. Proc Natl Acad Sci USA 98: 2658-2663

Sato N, Gleave ME, Bruchovsky N, Rennie PS, Beraldi E, Sullivan LD (1997) A metastatic and androgen-sensitive human prostate cancer model using intraprostatic inoculation of LNCaP cells in SCID mice. Cancer Res 57: $1584-1589$

Shariat SF, Roehrborn CG, McConnell JD, Park S, Alam N, Wheeler TM, Slawin KM (2007) Association of the circulating levels of the urokinase system of plasminogen activation with the presence of prostate cancer and invasion, progression, and metastasis. J Clin Oncol 25: 349-355

Sofer M, Savoie M, Kim SS, Civantos F, Soloway MS (2003) Biochemical and pathological predictors of the recurrence of prostatic 
adenocarcinoma with seminal vesicle invasion. J Urol 169: $153-156$

Tuxhorn JA, McAlhany SJ, Yang F, Dang TD, Rowley DR (2002) Inhibition of transforming growth factor-beta activity decreases angiogenesis in a human prostate cancer-reactive stroma xenograft model. Cancer Res 62: $6021-6025$

Unlu A, Leake RE (2003) Transforming growth factor $\beta 1$ stimulates urokinase plasminogen activator system on prostate cancer cells. Int $J$ Biol Markers 18: $147-151$
Usher PA, Thomsen OF, Iversen P, Johnsen M, Brunner N, Hoyer-Hansen G, Andreasen P, Dano K, Nielsen BS (2005) Expression of urokinase plasminogen activator, its receptor and type-1 inhibitor in malignant and benign prostate tissue. Int J Cancer 113: 870-880

Yamanaka K, Gleave ME, Hara I, Muramaki M, Miyake H (2005) Synergistic antitumor effect of combined use of adenoviral-mediated p53 gene transfer and antisense oligodeoxynucleotide targeting clusterin gene in an androgen-independent human prostate cancer model. Mol Cancer Ther 4: 187-195 